\title{
Pendekatan Penentuan Bobot dengan Surrogate Weighting Procedures untuk Metode Simple Additive Weighting dalam Pengambilan Keputusan Multikriteria
}

\author{
I Gede Iwan Sudipa ${ }^{* 1}$, Komang Sri Aryati ${ }^{2}$ \\ 1,2 Teknik Informatika, STMIK STIKOM Indonesia, Denpasar, Indonesia
}

\section{A R T I C L E I N F O}

Article history:

Received 19 July 2019

Received in revised form

16 August 2019

Accepted 19 September 2019

Available online 30 October 2019

Kata Kunci:

Multikriteria,Surrogate

Weight, SAW

Keywords:

Multicriteria, Surrogate

Weight, SAW

\begin{abstract}
A B S T R A K
Penentuan bobot multikriteria dalam pengambilan keputusan menjadi suatu kesulitan bagi pengambil keputusan, penentuan bobot diperlukan untuk melakukan evaluasi kriteria. Namun dalam beberapa situasi pengambil keputusan tidak percaya diri atau tidak memiliki pengetahuan untuk mendefinisikan nilai preferensi untuk bobot dan lebih menyukai menggunakan informasi parsial dan penilaian subyektif terhadap bobot kriteria. Salah satu cara penentuan bobot adalah dengan menentukan urutan prioritas kriteria dan menggunakan Surrogate Weight (bobot pengganti) untuk menentukan bobot sesuai dengan jumlah kriteria yang digunakan. Dalam penelitian ini mengimplementasikan Surrogate Weight Procedures yang terdiri dari Rank Sum(RS), Rank Reciprocal(RR), Rank Order Centroid(ROC) dan Equal Weight(EW) untuk menentukan bobot dan metode Simple Additive Weighting (SAW) untuk melakukan perankingan. Simulasi kasus yang digunakan yaitu seleksi pemberian beasiswa PPA (Peningkatan Prestasi Akademik) dengan 9 kriteria dan 22 alternatif. Hasil pengujian dalam penelitian ini yaitu analisis perbandingan hasil akhir alternatif dari kombinasi metode RS-SAW, RR-SAW, ROC-SAW dan EW-SAW .
\end{abstract}

\section{A B S T R A C T}

Determination of multi-criteria weighting in decision making becomes a difficulty for decision makers, determination of weights is needed to evaluate criteria. But in some situations decision makers do not confidently define preference values for weights and prefer to use partial information and subjective assessments of criteria weights. One way to determine weights is to determine the priority order of the criteria and using surrogate weight to determine the weight according to the number of criteria used. In this study, the Surrogate Weight Method consists of Rank Sum(RS), Reciprocal Rank(RR), Rank Order Centroid(ROC) and Equal Weight(EW) to determine weights and the Simple Additive Weighting (SAW) method for ranking. Case simulation used is the selection of the awarding of PPA scholarships (Peningkatan Prestasi Akademik) with 9 criteria and 22 alternatives. Test Result of this researches is comparison analyzes of alternative final results from combination method of RS-SAW, RR-SAW, ROC-SAW and EW-SAW.

\footnotetext{
* Corresponding author.

E-mail addresses: iwansudipa@stiki-indonesia.ac.id (I Gede Iwan Sudipa)
} 


\section{Pendahuluan}

Dalam banyak kasus pengambilan keputusan seringkali alternatif terbaik tidak dapat ditentukan secara langsung karena adanya pertimbangan konflik atau perbandingan antar kriteria yang digunakan sebagai penilaian (1). Berbagai metode dalam Multi Criteria Decision Analysis (MCDA) telah banyak digunakan untuk menyelesaikan masalah pengambilan keputsan terutama permasalahan multikriteria. Sebagian besar metode MCDA digunakan dengan syarat bahwa setiap kriteria berperan dalam menentukan hasil keputusan atau alternatif terbaik berdasarkan bobot kriteria. Bobot yang relatif dihasilkan sangat dipengaruhi oleh metode elicitation atau surrogate (pengganti) yang digunakan dalam menentukan bobot, karena itu pengambil keputusan diharuskan dapat menetapkan bobot setiap kriteria karena sangat penting dalam pengambilan keputusan(2). Namun dalam beberapa situasi pengambil keputusan tidak percaya diri atau tidak memiliki pengetahuan mendefinisikan nilai preferensi secara spesifik untuk bobot dan lebih menyukai menggunakan informasi parsial dan penilaian subyektif terhadap bobot kriteria sehingga teknik yang bisa dilakukan yaitu dengan surrogate (pengganti) pengambil keputusan dapat menentukan nilai bobot hanya berdasarkan urutan prioritas kriteria dari yang paling diprioritaskan ataupun melihat derajat kepentingan sama pada setiap kriteria(3).

Banyak metode telah disarankan dalam banyak literatur yang membahas pengambilan keputusan dengan metode MCDA khususnya menentukan nilai bobot dengan melihat prioritas kriteria, diantaranya yaitu metode pembobotan berbasis peringkat (Rank based weighting) yang mengubah urutan kriteria menjadi bobot numerik, dalam penerapannya Rank based weighting menggunakan prosedur pengganti bobot (Surrogate Weghting Procedures) untuk menentukan nilai preferensi pengambil keputusan berdasarkan prioritas atau peringkat kriteria(4). Adapun metode lainnya adalah metode yang membutuhkan penilaian pengambil keputusan dalam menetapkan nilai untuk mencermikan derajat kepentingan kriteria, seperti metode AHP, SWING, Point Allocation atau Direct Rating (5). Penilaian pengambil keputusan sangat diperlukan karena sejumlah alasan yaitu mereka tidak memiliki pemahaman yang memadai untuk menetapkan nilai preferensi sehingga penilaian cenderung subyektif dan tidak jelas. Disisi lain, hanya memikirkan prioritas kriteria lebih mudah karena peringkat kriteria adalah langkah awal untuk banyak metode pembobotan(6).

Ketika pengambilan keputusan lebih percaya diri untuk hanya memprioritaskan kriteria, maka bobot yang diperoleh informasi harus dapat dihandalkan dalam menentukan alternatif terbaik. Surrogate Weighting Procedures sesuai dengan situasi dimana terdapat batasan waktu dalam pengambilan keputusan dan pengambil keputusan dirasa tidak memiliki informasi secara keseluruhan (parsial), bobot hanya mewakili tingkat kepentingan kriteria, tidak adanya perbandingan trade-off antar kriteria dan skala bobot kriteria yang belum ditentukan(7)(8). Terdapat banyak perhitungan matematika yang digunakan untuk mengganti urutan peringkat kriteria menjadi nilai bobot (9) seperti Rank Sum (RS), Rank Reciprocal (RR), Rank Order Centroid (ROC) dan Equal Weight (EW).

Sesuai dengan permasalahan diatas maka dalam penelitian ini dijelaskan penerapan prosedur pengganti bobot (Surrogate Weghting Procedures) dengan peringkat atau prioritas kriteria dalam penentuan seleksi penerima beasiswa, metode yang digunakan untuk menentukan bobot kriteria yaitu RS, RR, ROC dan EW serta untuk melakukan perankingan menggunakan SAW, sehingga menghasilkan perankingan dapat dilakukan perbandingan hasil alternatif terbaik dengan nilai bobot yang dihasilkan setiap metode.

\section{Metode}

Dari hasil pengumpulan data yaitu observasi dan wawancara dengan Pembantu Ketua III STMIK STIKOM Indonesia, maka diperoleh data dalam penelitian yaitu data pemohon beasiswa Peningkatan Prestasi Akademik (PPA) mahasiswa STMIK STIKOM Indonesia tahun 2016/2017 sebanyak 22 mahasiswa. kriteria penilaian seleksi beasiswa yang digunakan terdiri dari IPK (K1), Prestasi Akademik (K2), Jumlah Semester (K3), Prestasi Non Akademik (K4), Keaktifan Organisasi (K5), Jumlah Seminar bidang Teknologi Informasi yang diikuti (K6), Jumlah Penghasilan Orangtua (K7), Jumlah Tanggungan Orangtua(K8), dan Daya Listrik (K9) sesuai dengan penelitian penulis sebelumnya(17). Tahap awal ditentukan sifat kriteria yang nantinya akan digunakan dalam perhitungan metode SAW, sifat kriteria dapat ditunjukkan pada Tabel 1. 
Tabel 1. Sifat Kriteria

\begin{tabular}{clc}
\hline Variabel Kriteria & \multicolumn{1}{c}{ Kriteria } & Sifat Kriteria \\
\hline B & IPK & Benefit \\
K2 & Prestasi Akademik & Benefit \\
K3 & Jumlah Semester & Benefit \\
K4 & Prestasi Non Akademik & Benefit \\
K5 & Keaktifan Organisasi & Benefit \\
K6 & Jumlah Seminar bidang teknologi informasi & Benefit \\
K7 & yang diikuti & Cost \\
K8 & Jumlah Penghasilan Orangtua & Cost \\
K9 & Jumlah Tanggungan Orangtua & Cost \\
\hline
\end{tabular}

\section{Hasil dan Pembahasan}

Pengujian metode dalam penelitian difokuskan untuk mengetahui penerapan Surrogate Weghting pada metode SAW dan hasil akhir alternatif terbaik, pengujian hasil dilakukan dengan menghitung hasil akhir setiap metode dan melakukan perbandingan hasil yang dilakukan dalam beberapa tahapan, sebagai berikut :

\section{A. Perhitungan Nilai Bobot Metode EW, RS, RR dan ROC}

Tahap selanjutnya menentukan nilai bobot tiap kriteria dengan metode EW, RS, RR dan ROC sesuai dengan Persamaan (1), Persamaan (2), Persamaan (3) dan Persamaan (6), . Hasil perhitungan nilai bobot dapat ditunjukkan pada Tabel 2 .

Tabel 2. Perbandingan Hasil Nilai Bobot

\begin{tabular}{ccccc}
\hline \multirow{2}{*}{ Kriteria (n) } & EW & RS & RR & ROC \\
\cline { 2 - 5 } & 0,1111 & 0,2 & 0,3535 & 0,3143 \\
$\mathrm{n}=1$ & 0,1111 & 0,1778 & 0,1767 & 0,2032 \\
$\mathrm{n}=2$ & 0,1111 & 0,1556 & 0,1178 & 0,1477 \\
$\mathrm{n}=3$ & 0,1111 & 0,1333 & 0,0884 & 0,1106 \\
$\mathrm{n}=4$ & 0,1111 & 0,1111 & 0,0707 & 0,0828 \\
$\mathrm{n}=5$ & 0,1111 & 0,0889 & 0,0589 & 0,0606 \\
$\mathrm{n}=6$ & 0,1111 & 0,0667 & 0,0505 & 0,0421 \\
$\mathrm{n}=7$ & 0,1111 & 0,0444 & 0,0442 & 0,0262 \\
$\mathrm{n}=8$ & 0,1111 & 0,0222 & 0,0393 & 0,0123 \\
$\mathrm{n}=9$ & & & & \\
\hline
\end{tabular}

Untuk mengetahui perbandingan hasil nilai bobot untuk metode EW, RS, RR dan ROC maka dapat ditunjukkan pada Gambar (1) :

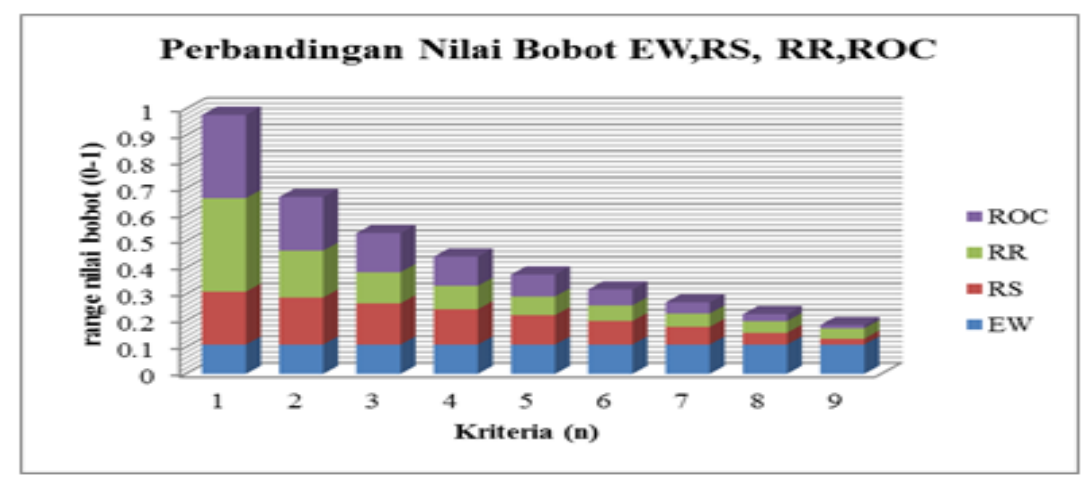

Gambar 1. Grafik Perbandingan Nilai Bobot 
Selanjutnya ditampilkan data pemohon beasiswa PPA tahun 2016/2017, alternatif pemohon beasiswa sebanyak 22 alternatif, dengan nilai alternatif terhadap kriteria yang sudah dilakukan skoring data ke dalam nilai numerik. Data mahasiswa dapat ditunjukkan pada Tabel 3.

Tabel 3. Data Mahasiswa Pemohon Beasiswa PPA tahun 2016/2017

\begin{tabular}{lccccccccc}
\hline \multirow{2}{*}{\multicolumn{1}{c}{ Alternatif }} & \multicolumn{9}{c}{ Kriteria } \\
\cline { 2 - 10 } K1 & K2 & K3 & K4 & K5 & K6 & K7 & K8 & K9 \\
\hline Mahesa & 3,81 & 0,9133 & 6 & 0,0625 & 2 & 1 & 5 & 1 & 2 \\
Ester & 3,95 & 0,3133 & 6 & 0,0625 & 2 & 2 & 3 & 1 & 2 \\
Lely & 3,82 & 0,04 & 4 & 0,2917 & 2 & 2 & 1 & 2 & 2 \\
Lestari & 3,71 & 0,5133 & 4 & 0,0625 & 2 & 2 & 2 & 2 & 2 \\
Lina & 3,9 & 0,04 & 4 & 0,4375 & 2 & 2 & 2 & 2 & 2 \\
Yoseph & 3,75 & 0,04 & 4 & 0,2708 & 2 & 1 & 3 & 2 & 2 \\
Julius & 3,79 & 0,04 & 4 & 0,2708 & 2 & 1 & 1 & 3 & 2 \\
Christopher & 3,86 & 0,04 & 6 & 1,0417 & 2 & 1 & 2 & 2 & 2 \\
Rahmawati & 3,58 & 0,04 & 6 & 0,5417 & 2 & 2 & 1 & 1 & 2 \\
Jonathan & 3,38 & 0,04 & 6 & 2,0833 & 2 & 1 & 1 & 1 & 2 \\
Yusuf & 3,52 & 1,2833 & 4 & 0,0625 & 2 & 2 & 2 & 2 & 2 \\
Dian & 3,48 & 0,04 & 6 & 0,2708 & 2 & 2 & 1 & 1 & 2 \\
Ayudani & 3,88 & 0,47 & 4 & 0,0625 & 2 & 2 & 3 & 2 & 2 \\
Ita Miranti & 3,65 & 0,04 & 4 & 1,5625 & 2 & 2 & 1 & 3 & 2 \\
Yulia & 3,66 & 0,04 & 4 & 0,2708 & 2 & 2 & 2 & 2 & 2 \\
Wirawan & 3,7 & 0,18 & 6 & 0,0625 & 2 & 1 & 3 & 2 & 2 \\
Dessie & 3,51 & 0,04 & 4 & 0,2917 & 2 & 2 & 5 & 2 & 2 \\
Juniastini & 3,96 & 0,18 & 4 & 0,0625 & 2 & 2 & 2 & 3 & 2 \\
Selfiana & 3,69 & 0,3133 & 4 & 0,0625 & 2 & 2 & 2 & 2 & 2 \\
Prasetya & 3,36 & 0,18 & 6 & 0,0625 & 2 & 2 & 3 & 2 & 2 \\
Caniartana & 3,37 & 0,04 & 4 & 0,0625 & 2 & 1 & 2 & 2 & 2 \\
Juliana & 3,34 & 0,04 & 4 & 0,0625 & 2 & 1 & 2 & 1 & 2 \\
\hline
\end{tabular}

\section{B. Perankingan Metode EW dan SAW}

Tahap awal sebelum melakukan perankingan adalah melakukan normalisasi nilai alternatif pada setiap kriteria sesuai dengan sifat kriteria yaitu K1,K2,K3,K4,K5,K6 yaitu benefit, sedangkan K7,K8,K9 yaitu cost, proses normalisasi dihitung dengan menggunakan Persamaan (8), sehingga didapatkan hasil normalisasi dapat ditunjukkan pada Tabel 4.

Tabel 4. Nilai Normalisasi

\begin{tabular}{lccccccccc}
\hline \multirow{2}{*}{\multicolumn{1}{c}{ Alternatif }} & \multicolumn{9}{c}{ Kriteria } \\
\cline { 2 - 10 } & K1 & K2 & K3 & K4 & K5 & K6 & K7 & K8 & K9 \\
\hline Mahesa & 0.9621 & 0.7117 & 1 & 0.03 & 1 & 0.5 & 1 & 0.333 & 1 \\
Ester & 0.9975 & 0.2442 & 1 & 0.03 & 1 & 1 & 0.6 & 0.333 & 1 \\
Lely & 0.9646 & 0.0312 & 0.6667 & 0.14 & 1 & 1 & 0.2 & 0.667 & 1 \\
Lestari & 0.9369 & 0.4 & 0.6667 & 0.03 & 1 & 1 & 0.4 & 0.667 & 1 \\
Lina & 0.9848 & 0.0312 & 0.6667 & 0.21 & 1 & 1 & 0.4 & 0.667 & 1 \\
Yoseph & 0.947 & 0.0312 & 0.6667 & 0.13 & 1 & 0.5 & 0.6 & 0.667 & 1 \\
Julius & 0.9571 & 0.0312 & 0.6667 & 0.13 & 1 & 0.5 & 0.2 & 1 & 1 \\
Christopher & 0.9747 & 0.0312 & 1 & 0.5 & 1 & 0.5 & 0.4 & 0.667 & 1 \\
Rahmawati & 0.904 & 0.0312 & 1 & 0.26 & 1 & 1 & 0.2 & 0.333 & 1 \\
Jonathan & 0.8535 & 0.0312 & 1 & 1 & 1 & 0.5 & 0.2 & 0.333 & 1 \\
Yusuf & 0.8889 & 1 & 0.6667 & 0.03 & 1 & 1 & 0.4 & 0.667 & 1 \\
Dian & 0.8788 & 0.0312 & 1 & 0.13 & 1 & 1 & 0.2 & 0.333 & 1 \\
Ayudani & 0.9798 & 0.3662 & 0.6667 & 0.03 & 1 & 1 & 0.6 & 0.667 & 1 \\
Ita Miranti & 0.9217 & 0.0312 & 0.6667 & 0.75 & 1 & 1 & 0.2 & 1 & 1 \\
\hline
\end{tabular}




\begin{tabular}{lccccccccc}
\hline \multirow{2}{*}{ Alternatif } & \multicolumn{1}{c}{ Kriteria } \\
\cline { 2 - 10 } & K1 & K2 & K3 & K4 & K5 & K6 & K7 & K8 & K9 \\
\hline Yulia & 0.9242 & 0.0312 & 0.6667 & 0.13 & 1 & 1 & 0.4 & 0.667 & 1 \\
Wirawan & 0.9343 & 0.1403 & 1 & 0.03 & 1 & 0.5 & 0.6 & 0.667 & 1 \\
Dessie & 0.8864 & 0.0312 & 0.6667 & 0.14 & 1 & 1 & 1 & 0.667 & 1 \\
Juniastini & 1 & 0.1403 & 0.6667 & 0.03 & 1 & 1 & 0.4 & 1 & 1 \\
Selfiana & 0.9318 & 0.2442 & 0.6667 & 0.03 & 1 & 1 & 0.4 & 0.667 & 1 \\
Prasetya & 0.8485 & 0.1403 & 1 & 0.03 & 1 & 1 & 0.6 & 0.667 & 1 \\
Caniartana & 0.851 & 0.0312 & 0.6667 & 0.03 & 1 & 0.5 & 0.4 & 0.667 & 1 \\
Juliana & 0.8434 & 0.0312 & 0.6667 & 0.03 & 1 & 0.5 & 0.4 & 0.333 & 1 \\
\hline
\end{tabular}

Untuk menghitung nilai perankingan metode EW dan SAW maka nilai alternatif pada setiap kriteria sesuai Tabel 3, nilai alternatif dikalikan dengan bobot yang dihasilkan metode EW sesuai dengan Tabel 2, selanjutnya dilakukan penambahan nilai normalisasi dikalikan bobot untuk setiap kriteria sesuai dengan Persamaan (10), dari perhitungan tersebut menghasilkan ranking alternatif ditunjukkan pada Tabel 5.

Tabel 5. Hasil Perankingan Metode EW-SAW

\begin{tabular}{lcc}
\hline \multicolumn{1}{c}{ Alternatif } & Nilai Akhir & Ranking \\
\hline Mahesa & 0.7263 & 3 \\
Ester & 0.6894 & 8 \\
Lely & 0.6298 & 17 \\
Lestari & 0.6777 & 9 \\
Lina & 0.6621 & 11 \\
Yoseph & 0.6157 & 19 \\
Julius & 0.6094 & 20 \\
Christopher & 0.6747 & 10 \\
Rahmawati & 0.6364 & 16 \\
Jonathan & 0.6575 & 13 \\
Yusuf & 0.7391 & 1 \\
Dian & 0.6192 & 18 \\
Ayudani & 0.701 & 5 \\
Ita Miranti & 0.7299 & 2 \\
Yulia & 0.6465 & 15 \\
Wirawan & 0.6523 & 14 \\
Dessie & 0.71 & 4 \\
Juniastini & 0.6929 & 7 \\
Selfiana & 0.6599 & 12 \\
Prasetya & 0.6983 & 6 \\
Caniartana & 0.5717 & 21 \\
Juliana & 0.5338 & 22 \\
\hline
\end{tabular}

\section{Perhitungan Perankingan Metode RS dan SAW}

Untuk menghitung nilai perankingan metode EW dan SAW maka nilai alternatif pada setiap kriteria sesuai Tabel 3, nilai alternatif dikalikan dengan bobot yang dihasilkan metode EW sesuai dengan Tabel 2, selanjutnya dilakukan penambahan nilai normalisasi dikalikan bobot untuk setiap kriteria sesuai dengan Persamaan (10), dari perhitungan tersebut menghasilkan ranking alternatif ditunjukkan pada Tabel 6.

Tabel 6. Hasil Perankingan Metode RS-SAW

\begin{tabular}{|c|c|c|}
\hline Alternatif & Nilai Akhir & Ranking \\
\hline Mahesa & 0.7378 & 2 \\
\hline Ester & 0.6795 & 3 \\
\hline Lely & 0.586 & 18 \\
\hline Lestari & 0.6447 & 9 \\
\hline Lina & 0.6127 & 15 \\
\hline Yoseph & 0.5634 & 19 \\
\hline
\end{tabular}




\begin{tabular}{lcc}
\hline \multicolumn{1}{c}{ Alternatif } & Nilai Akhir & Ranking \\
\hline Julius & 0.5535 & 20 \\
Christopher & 0.6568 & 7 \\
Rahmawati & 0.6269 & 10 \\
Jonathan & 0.671 & 5 \\
Yusuf & 0.7418 & 1 \\
Dian & 0.6046 & 16 \\
Ayudani & 0.6606 & 6 \\
Ita Miranti & 0.6735 & 4 \\
Yulia & 0.5899 & 17 \\
Wirawan & 0.6188 & 13 \\
Dessie & 0.6237 & 12 \\
Juniastini & 0.626 & 11 \\
Selfiana & 0.616 & 14 \\
Prasetya & 0.6461 & 8 \\
Caniartana & 0.5175 & 21 \\
Juliana & 0.5012 & 22 \\
\hline
\end{tabular}

\section{Perhitungan Perankingan Metode RR dan SAW}

Untuk menghitung nilai perankingan metode EW dan SAW maka nilai alternatif pada setiap kriteria sesuai Tabel 3, nilai alternatif dikalikan dengan bobot yang dihasilkan metode EW sesuai dengan Tabel 2, selanjutnya dilakukan penambahan nilai normalisasi dikalikan bobot untuk setiap kriteria sesuai dengan Persamaan (10), dari perhitungan tersebut menghasilkan ranking alternatif ditunjukkan pada Tabel 7.

Tabel 7. Hasil Perankingan Metode RR-SAW

\begin{tabular}{lcc}
\hline \multicolumn{1}{c}{ Alternatif } & Nilai Akhir & Ranking \\
\hline Mahesa & 0.791 & 1 \\
Ester & 0.7301 & 3 \\
Lely & 0.6459 & 16 \\
Lestari & 0.7016 & 5 \\
Lina & 0.6693 & 13 \\
Yoseph & 0.6295 & 19 \\
Julius & 0.6276 & 20 \\
Christopher & 0.7012 & 6 \\
Rahmawati & 0.6596 & 14 \\
Jonathan & 0.6777 & 9 \\
Yusuf & 0.7907 & 2 \\
Dian & 0.6392 & 18 \\
Ayudani & 0.7209 & 4 \\
Ita Miranti & 0.6994 & 7 \\
Yulia & 0.6408 & 17 \\
Wirawan & 0.6747 & 10 \\
Dessie & 0.6586 & 15 \\
Juniastini & 0.6928 & 8 \\
Selfiana & 0.6723 & 12 \\
Prasetya & 0.6738 & 11 \\
Caniartana & 0.5766 & 21 \\
Juliana & 0.5592 & 22 \\
\hline
\end{tabular}




\section{E. Perhitungan Perankingan Metode ROC dan SAW}

Untuk menghitung nilai perankingan metode EW dan SAW maka nilai alternatif pada setiap kriteria sesuai Tabel 3, nilai alternatif dikalikan dengan bobot yang dihasilkan metode EW sesuai dengan Tabel 2, selanjutnya dilakukan penambahan nilai normalisasi dikalikan bobot untuk setiap kriteria sesuai dengan Persamaan (10), dari perhitungan tersebut menghasilkan ranking alternatif ditunjukkan pada Tabel 8.

Tabel 8. Hasil Perankingan Metode ROC-SAW

\begin{tabular}{lcc}
\hline \multicolumn{1}{c}{ Alternatif } & Nilai Akhir & Ranking \\
\hline Mahesa & 0.7744 & 2 \\
Ester & 0.704 & 3 \\
Lely & 0.6052 & 17 \\
Lestari & 0.6677 & 8 \\
Lina & 0.6277 & 14 \\
Yoseph & 0.5851 & 19 \\
Julius & 0.5802 & 20 \\
Christopher & 0.6755 & 6 \\
Rahmawati & 0.6399 & 12 \\
Jonathan & 0.6756 & 5 \\
Yusuf & 0.7745 & 1 \\
Dian & 0.6176 & 15 \\
Ayudani & 0.6827 & 4 \\
Ita Miranti & 0.668 & 7 \\
Yulia & 0.5998 & 18 \\
Wirawan & 0.6414 & 11 \\
Dessie & 0.6143 & 16 \\
Juniastini & 0.6435 & 10 \\
Selfiana & 0.6344 & 13 \\
Prasetya & 0.6448 & 9 \\
Caniartana & 0.5354 & 21 \\
Juliana & 0.5243 & 22 \\
\hline
\end{tabular}

\section{F. Perbandingan Hasil Perankingan Metode EW, RS, RR, ROC dan SAW}

Selanjutnya dilakukan perbandingan hasil perankingan dari kombinasi metode EW, RS, RR, ROC dan SAW. Perbandingan ini ditujukan untuk mengetahui perbedaan hasil perankingan alternatif. Hasil perbandingan hasil perankingan metode EW-SAW, RR-SAW ,RS-SAW dan ROC-SAW ditunjukkan pada Tabel 9.

Tabel 9. Hasil Perbandingan Perankingan Altenatif

\begin{tabular}{cccccc}
\hline Alternatif (A) & Nama & EW-SAW & RS-SAW & RR-SAW & ROC-SAW \\
\hline $\mathrm{A}_{1}$ & Mahesa & 3 & 2 & 1 & 2 \\
$\mathrm{~A}_{2}$ & Ester & 8 & 3 & 3 & 3 \\
$\mathrm{~A}_{3}$ & Lely & 17 & 18 & 16 & 17 \\
$\mathrm{~A}_{4}$ & Lestari & 9 & 9 & 5 & 8 \\
$\mathrm{~A}_{5}$ & Lina & 11 & 15 & 13 & 14 \\
$\mathrm{~A}_{6}$ & Yoseph & 19 & 19 & 19 & 19 \\
$\mathrm{~A}_{7}$ & Julius & 20 & 20 & 20 & 20 \\
$\mathrm{~A}_{8}$ & Christopher & 10 & 7 & 6 & 6 \\
$\mathrm{~A}_{9}$ & Rahmawati & 16 & 10 & 14 & 12 \\
$\mathrm{~A}_{10}$ & Jonathan & 13 & 5 & 9 & 5 \\
$\mathrm{~A}_{11}$ & Yusuf & 1 & 1 & 2 & 1 \\
$\mathrm{~A}_{12}$ & Dian & 18 & 16 & 18 & 15 \\
$\mathrm{~A}_{13}$ & Ayudani & 5 & 6 & 4 & 4 \\
$\mathrm{~A}_{14}$ & Ita Miranti & 2 & 4 & 7 & 7 \\
$\mathrm{~A}_{15}$ & Yulia & 15 & 17 & 17 & 18 \\
$\mathrm{~A}_{16}$ & Wirawan & 14 & 13 & 10 & 11 \\
$\mathrm{~A}_{17}$ & Dessie & 4 & 12 & 15 & 16 \\
\hline
\end{tabular}




\begin{tabular}{cccccc}
\hline Alternatif (A) & Nama & EW-SAW & RS-SAW & RR-SAW & ROC-SAW \\
\hline $\mathrm{A}_{18}$ & Juniastini & 7 & 11 & 8 & 10 \\
$\mathrm{~A}_{19}$ & Selfiana & 12 & 14 & 12 & 13 \\
$\mathrm{~A}_{20}$ & Prasetya & 6 & 8 & 11 & 9 \\
$\mathrm{~A}_{21}$ & Caniartana & 21 & 21 & 21 & 21 \\
$\mathrm{~A}_{22}$ & Juliana & 22 & 22 & 22 & 22 \\
\hline
\end{tabular}

Pada hasil akhir perankingan didapatkan hasil bahwa terdapat perbedaan hasil alternatif terbaik untuk metode EW-SAW, RS-SAW dan ROC-SAW menunjukkan alternatif $A_{11}$ sebagai alternatif terbaik, sedangkan metode RR-SAW menunjukkan alternatif $A_{1}$ sebagai alternatif terbaik, ini disebabkan karena hasil nilai bobot RR-SAW untuk K1 paling besar dibandingkan dengan bobot yang dihasilkan metode lain, sesuai dengan Tabel 2.

Jika dilihat dari hasil perankingan 10 mahasiswa terbaik maka terdapat urutan ranking alternatif (A) yang dihasilkan, perbedaannya dapat ditunjukkanpada Tabel 10, sebagai berikut .

Tabel 10. Perbandingan Perankingan Alternatif Berdasarkan 4 Metode

\begin{tabular}{cc}
\hline Metode & Ranking Alternatif \\
\hline EW-SAW & $A_{11}>A_{14}>A_{1}>A_{17}>A_{13}>A_{20}>A_{18}>A_{2}>A_{4}>A_{8}$ \\
RS-SAW & $A_{11}>A_{1}>A_{2}>A_{14}>A_{10}>A_{13}>A_{8}>A_{20}>A_{4}>A_{9}$ \\
RR-SAW & $A_{1}>A_{11}>A_{2}>A_{13}>A_{4}>A_{8}>A_{14}>A_{18}>A_{10}>A_{16}$ \\
ROC-SAW & $A_{11}>A_{1}>A_{13}>A_{13}>A_{10}>A_{8}>A_{14}>A_{4}>A_{20}>A_{18}$ \\
\hline
\end{tabular}

Hasil perbandingan perankingan alternatif dari 4 metode menunjukkan perbedaan urutan ranking alternatif, perbedaan ini menunjukkan bahwa perbedaan bobot tiap metode sangat mempengaruhi hasil akhir perankingan, karena nilai alternatif terhadap kriteria berbeda sehingga dengan menggunakan metode SAW terdapat proses perkalian nilai alternatif ternormalisasi dengan nilai bobot, sehingga menyebabkan perbedaan hasil akhir.

\section{Simpulan dan Saran}

Kesimpulan dari penelitian yaitu dalam penentuan bobot kriteria dengan metode EW, RS, RR dan ROC mampu memudahkan pengambil keputusan yang tidak bisa menentukan tingkat kepentingan dari kriteria yang digunakan dalam pengambilan keputusan, teknik perhitungan Surrogate Weighting ini mampu merubah tingkat prioritas kriteria menjadi nilai bobot dalam angka numerik dengan perhitungan yang sederhana namun tetap memperhitungkan hubungan antara tingkat prioritas kriteria( $i)$ dengan jumlah kriteria( $n)$. Hasil pengujian dan analisis perhitungan pada penelitian ini menunjukkan metode EW, RS, RR dan ROC dapat dikombinasikan dengan metode SAW untuk menghasilkan alternatif terbaik penerima beasiswa PPA, analisis hanya mencakup melakukan perbandingan hasil akhir dari kombinasi metode EW-SAW,RS-SAW,RR-SAW,ROC-SAW dan terdapat perbedaan perankingan yang disebabkan nilai bobot yang dihasilkan setiap metode sehingga sangat mempengaruhi hasil akhir perankingan alternatif.

Saran dari penulis guna pengembangan penelitian lebih lanjut yaitu perlu dilakukan analisis sensitivitas untuk setiap kombinasi metode untuk menentukan metode yang paling sensitif terhadap perubahan nilai bobot, melakukan analisis sensivititas terhadap kriteria sehingga dapat mengetahui kriteria yang paling kritis dan mempengaruhi perubahan hasil akhir perankingan alternatif. Serta dapat mengimplementasikan teknik Surrogate Weighting untuk menyelesaikan permasalahan penentuan nilai bobot dalam pengambilan keputusan dengan banyak kriteria lainnya.

\section{Daftar Rujukan}

Ahn BS. Approximate weighting method for multiattribute decision problems with imprecise parameters. Omega (United Kingdom). 2017

Antunes $\mathrm{CH}$, Henriques CO. Multi-objective optimization and multi-criteria analysis models and methods for problems in the energy sector. Int Ser Oper Res Manag Sci. 2016.

Danielson M, Ekenberg L. A Robustness Study of State-of-the-Art Surrogate Weights for MCDM. Gr Decis Negot. 2017;26(4):677-91. 
Dawes RM, Corrigan B. Linear models in decision making. Psychol Bull. 1974.

De Almeida AT, De Almeida JA, Costa APCS, De Almeida-Filho AT. A new method for elicitation of criteria weights in additive models: Flexible and interactive tradeoff. Eur J Oper Res. 2016.

Fishburn PC. Letter to the Editor-Additive Utilities with Incomplete Product Sets: Application to Priorities and Assignments. Oper Res. 1967;15(3):537-42.

I Gede Iwan Sudipa. Decision Support System Dengan Metode AHP, SAW dan ROC Untuk Penentuan Pemberian Beasiswa (Studi Kasus STMIK STIKOM INDONESIA). J Teknol Inf dan Komput. 2018;4(1):18-30.

Jenderal D, Dan P, Riset K, Tinggi DANP. Pedoman umum beasiswa dan bantuan biaya pendidikan peningkatan prestasi akademik (ppa). 2015.

Jia J, Fischer GW, Dyer JS. Attribute weighting methods and decision quality in the presence of response error: A simulation study. J Behav Decis Mak. 1998.

Krstić A. Figueira, J., Greco, S., Ehrgott, M.: Multicriteria Decision Analysis: State of the art Surveys, Springer-Verlag, New York, NY, 2016. Ekon horizonti. 2018;

Kunsch PL, Ishizaka A. Multiple-criteria performance ranking based on profile distributions: An application to university research evaluations. Math Comput Simul. 2018.

Kunsch PL, Ishizaka A. A note on using centroid weights in additive multi-criteria decision analysis. Eur J Oper Res. 2019.

Lu J, Wu D, Mao M, Wang W, Zhang G. Recommender system application developments: A survey. Decis Support Syst. 2015.

Morais DC, De Almeida AT, Alencar LH, Clemente TRN, Cavalcanti CZB. PROMETHEE-ROC model for assessing the readiness of technology for generating energy. Math Probl Eng. 2015.

Roszkowska E. Rank Ordering Criteria Weighting Methods - a Comparative Overview. Optimum Stud Ekon. 2013.

Stillwell WG, Seaver DA, Edwards W. A comparison of weight approximation techniques in multiattribute utility decision making. Organ Behav Hum Perform. 1981;28(1):62-77.

Sureeyatanapas P, Yang J-B, Bamford D. Analysis of criteria weights for the assessment of corporate sustainability: a case study in sugar manufacturing. KKU Eng J. 2016. 